\title{
Food and nutrition literacy status and its correlates in Iranian senior high-school students
}

\author{
Marziyeh Ashoori ${ }^{1}$, Nasrin Omidvar ${ }^{2}$, Hassan Eini-Zinab², Elham Shakibazadeh ${ }^{3}$, Azam Doustmohamadian ${ }^{4}$ \\ Behnaz Abdar-Esfahani ${ }^{2}$ and Mohammad Mazandaranian ${ }^{2}$
}

\begin{abstract}
Background: Planning interventions to promote food and nutrition literacy (FNL) require a better understanding of the FNL status of the target group and its correlates.

Aims: This study aimed to examine the FNL status and its determinants in Iranian senior high-school students.

Methods: In this cross-sectional study, FNL and its components (food and nutrition knowledge, functional skills, interactive skills, advocacy, critical analysis of information, and food label reading skill) were evaluated by a locally designed and validated, self-administered questionnaire. Besides, socioeconomic, demographic, anthropometric measures, as well as academic performance of 626 senior high-school students were assessed.
\end{abstract}

Results: The mean \pm SD of the total FNL score (within potential range of 0 to 100 ) was $52.1 \pm 10.96$, which is below the minimum adequate level of 60 . The probability of high FNL knowledge score was significantly higher among students who majored in Natural Sciences $(\mathrm{OR}=1.73, \mathrm{Cl}=1.09-2.75)$, had better school performance $(\mathrm{OR}=1.13$, $\mathrm{Cl}=1.06-1.20)$ and higher SES score $(\mathrm{OR}=1.20, \mathrm{Cl}=1.01-1.44)$. The score for food label reading was significantly lower in girls ( $\mathrm{OR}=0.45, \mathrm{Cl}=0.31-0.67)$, while those who had a family member with the nutrition-related disease were more likely to have a higher score of food label reading skill $(\mathrm{OR}=1.48, \mathrm{Cl}=1.01-1.64)$.

Conclusion: The level of FNL in senior high-school students in Tehran was relatively low. These findings have key messages for the education system and curriculum designers to have more consideration for food and nutritionrelated knowledge and skills in schools.

Keywords: Food literacy, Iran, Nutrition literacy, Young adults

\footnotetext{
* Correspondence: omidvar.nasrin@gmail.com

2Department of Community Nutrition, National Nutrition and Food Technology Research Institute (NNFTRI) and Faculty of Nutrition Sciences and Food Technology, Shahid Beheshti University of Medical Sciences, West Arghavan St. Farahzadi Blvd., Sharake Qods, Tehran, Iran

Full list of author information is available at the end of the article
}

(C) The Author(s). 2021 Open Access This article is licensed under a Creative Commons Attribution 4.0 International License, which permits use, sharing, adaptation, distribution and reproduction in any medium or format, as long as you give appropriate credit to the original author(s) and the source, provide a link to the Creative Commons licence, and indicate if changes were made. The images or other third party material in this article are included in the article's Creative Commons licence, unless indicated otherwise in a credit line to the material. If material is not included in the article's Creative Commons licence and your intended use is not permitted by statutory regulation or exceeds the permitted use, you will need to obtain permission directly from the copyright holder. To view a copy of this licence, visit http://creativecommons.org/licenses/by/4.0/ The Creative Commons Public Domain Dedication waiver (http://creativecommons.org/publicdomain/zero/1.0/) applies to the data made available in this article, unless otherwise stated in a credit line to the data. 


\section{Introduction}

Unhealthy eating behavior is among the leading risk factors of non-communicable diseases (NCDs) [1], which were responsible for $71 \%$ of global deaths in 2016 [2]. Based on an estimate, in 2017, one in every 5 deaths was preventable through improving dietary intake globally [3]. Therefore, poor dietary practice is one of the major concerns of the health sector in both developed and developing countries. In this regard, adolescents' dietary behavior is particularly a concern, since poor dietary intakes are highly prevalent among this age group in both low- and middle-income countries [4]. In Iran, as a middle-income country, high consumption of fast foods and unhealthy snacks, skipping breakfast, and low intake of fruits, vegetables, whole grains, and dairy products have been reported as common inappropriate dietary practices among youth [5].

Previous studies has identified numerous determinants of diet quality, including demographics, socio-economic, environmental, and socio-cultural factors [6], as well as food and nutrition-related knowledge and skills [7]. Therefore, many nutrition education interventions have tried to promote healthy eating behavior(s); however, most of these interventions have had a traditional approach through focusing on nutrition knowledge rather than skills that have resulted in limited improvement in dietary intakes and/or practices [8].

Food literacy and nutrition literacy are the emerged concepts that address not only knowledge but skills about food and nutrition. Vidgen et al. have defined food literacy as the "collection of inter-related knowledge, skills and behaviors required to plan, manage, select, prepare and eat foods to meet needs and determine food intake" [9]. "Food literacy" and "nutrition literacy" are often used interchangeably [10]. Reviewing available literature indicates these concepts have considerable overlaps and complementarities, and aim at the same goal, i.e. promoting healthy and sustainable food choices. Therefore, it is hard to determine the definite border between "food literacy" and "nutrition literacy". It seems that "food and nutrition literacy" (FNL) is a more comprehensive term to describe the set of knowledge and skills by which people can "plan, manage, select, prepare and eat foods" [9] and "make appropriate nutrition decisions" [10].

Late adolescents and youth are in a transition stage between adolescence and adulthood and are starting to experience or have recently experienced independent living. Consequently, they start to have more responsibilities in planning, selecting and, preparing foods compared to younger ages. Therefore, the knowledge and skill level of this age group about food and nutrition could help them cope with the complex and multifaceted factors influencing their dietary practice and this could have a critical impact on their eating habits and health in later life. In this regard, the high-school period can be considered as the last opportunity for the formal education system to improve the FNL level of adolescents and prepare them for future life. Despite this fact, nutrition education is not incorporated properly and adequately in school curriculums in many countries, including Iran. A recent content analysis of high school textbooks and curriculums with regard to FNL in Iran showed that there is very limited attention given to different components of FNL, specifically skill domain [11]. Thus, assessing the FNL status of late adolescence and youth could provide valuable evidence about a major need in this age group and possible gaps in the education system to be considered for future interventions and/or high school curriculum revisions.

Quantitative research in the field of food and nutrition literacy are limited but growing [12-21]. There are a number of studies on the FNL status of different age groups, including adults $[12,13,17,20,21]$, youth [14, 19], adolescent [15, 18], and primary school children [16]. However, in many of these studies food or nutrition literacy is limited to nutrition knowledge [21], food label interpretation skill $[13,14]$, or both $[12,15,20]$. However, food and nutrition literacy as a multidimensional concept [22], encompasses much broader competencies, including food planning, shopping, budgeting, storage, and preparation skills, social aspects of eating, environmental sustainability, etc. [9]. Furthermore, no previous research has focused on FNL status of Iranian adolescents and youth and its components. Moreover, determinants of the FNL and its components in senior highschool students and youth are remained to be examined. Considering these gaps, the present study was carried out to examine the food and nutrition literacy status and its determinants in urban senior high-school students in Iran. The findings are expected to guide intervention planners in designing targeted and effective educational programs.

\section{Materials and methods}

This cross-sectional study was carried out from November 2017 to April 2018 in the metropolitan city of Tehran.

\section{Study sample}

The study participants were 755 senior high-school students (aged 17-18 years). Inclusion criteria included being enrolled in the senior high-school and willingness to participate. If a student was not interested to participate in the study or followed a special diet, he/she would be excluded from the study and were replaced by another student through random selection. The students were selected through the multistage cluster random sampling 
method. There are 19 educational districts in Tehran city which are classified into 3 socioeconomic levels, including: affluent (districts 1 to 6), semi-affluent (districts 7 to 14), and deprived (districts 15 to 19). Nine educational districts (3 from each socioeconomic level) were selected and the number of samples in each district, in private and public schools, from each sex and each study major (Natural Sciences, Mathematics, Literature, and Humanities) were determined according to the population proportion. The selection of educational districts and schools was performed through cluster random sampling and students were selected by stratified random sampling.

\section{Measures}

\section{Food and nutrition literacy}

FNL was assessed by a 60-item Food and Nutrition Literacy Assessment Tool (FNLAT). The questionnaire was developed and validated for high-school graduates and youth in the prior stages of this project. The process of development of FNLAT and its validation has been reported elsewhere [23]. We used FNLAT, as the only valid multidimensional questionnaire available for Iranian adolescents and youth. This self-administered questionnaire comprised of two domains (knowledge and skills) and six dimensions (food and nutrition knowledge (27 items), functional skills (11 items), interactive skills (7 items), advocacy (7 items), critical analysis of information (5 items), and food label reading skill (3tiems)). FNLAT included 30 binary questions on nutrition knowledge and food label reading skills and 30 Likert-type statements for assessing other dimensions of skill domain. The domains and dimensions of FNLAT were developed based on domains and dimensions of FNL identified through the preliminary qualitative phase of the study. The area of knowledge and skills assessed in the questionnaire are listed in the Additional file 1 . In addition, through construct validity assessment of the questionnaire, advocacy and critical analysis of information (the sub-dimensions of critical skills identified in qualitative phase), and food label reading skills items are included as two separate dimensions in FNLAT [23].

Total FNL score and each dimension's score ranged from 0 to 100 (sum of the raw scores were linearly transformed to a score from 0 to 100), with higher scores indicating higher FNL level. In this questionnaire, FNL scores lower than 45 are interpreted as poor and those higher than 60 are considered as adequate food and nutrition literacy. Scores from 45 to 60 were categorized as moderate level of food and nutrition literacy. FNLAT was completed by the students while they were at school.

\section{Anthropometric measurements}

Participants' weight was measured with minimum clothing, without shoes, using a digital scale (Seca) and recorded to the nearest $0.1 \mathrm{~kg}$. Height was assessed using a wall-fixed tape in standing position, without shoes while shoulders were in a normal position. BMI for age zscore was calculated by using WHO Anthro-Plus software. Obesity and overweight were defined based on WHO criteria.

\section{Socio-demographic variables and school performance}

Socio-demographic variables were measured using a questionnaire which was completed through interview with students. In order to evaluate socioeconomic status (SES), participants were asked about their family size, household head, parents age, education and job position; ownership (or type in some cases) of home appliances and facilities (TV, washing machine, dishwasher, refrigerator, microwave, number of cars in the family, number of computers or laptops), and residential house features (house area, number of rooms and house ownership status). If needed, complementary phone interviews were performed with parents.

Also, academic performance was assessed using grade point average (GPA) earned in the national final exams which are taken at the end of the high school.

\section{Statistical analysis}

Descriptive statistics of demographic and anthropometric variables were reported by frequencies and percentages of distribution for categorical variables and mean \pm $\mathrm{SD}$ for quantitative variables. Since several variables were measured as proxies of socioeconomic status (SES); in order to avoid multicollinearity in the regression model, principal component analysis (PCA) was applied to reduce socioeconomic variables into a unidimensional SES variable. The chi-square test was used to examine whether the distribution of categorical variables between boys and girls was significantly different. Student's t-test and One-Way ANOVA were applied to compare means and variances of quantitative variables with normal distribution; scores of total FNL, its domains, and dimensions; by sex and other categorical variables. Pearson and Spearman correlation coefficient was calculated to examine the bivariate association between FNL with continuous and ordinal variables, respectively. In order to identify predictors of high FNL, logistic regression was applied, where poor food and nutrition literacy (score $<45$ ) was considered as the reference group and adequate and moderate literacy were merged and considered as high FNL. The variables included in regression models as the possible predictors of FNL were: gender, study major, academic performance, SES score, presence of a nutrition-related disease in the participants 
or their family, and BMI-for-age z-score. The statistical significance level was set at $p<0.05$. SPSS 21.0 (SPSS Inc., Chicago, Illinois, USA) software was used to perform all statistical analysis.

\section{Results}

Of 755 students randomly selected, 621 provided all demographic and FNL data (response rate $=82.2 \%$ ). Among the students with completed demographic data $(n=626), 49.7 \%(n=311)$ were girls and $50.3 \%(n=315)$ were boys. A comparison between subjects who included in the analysis and excluded ones showed no significant difference in socio-demographic characteristics (parent education and job position, city district) $(p>0.05)$ except for gender. Of excluded subject, $58.2 \%$ were girls and $41.8 \%$ were boys $(p=0.04)$.

Demographic and anthropometric characteristics of the study participant are shown in Table 1 . The mean age of students was $17.82 \pm 0.39$ years. Education level in most of the parents was high school diploma or lower (74.2\% of mothers and $68.4 \%$ of fathers). There were no significant differences between boys' and girls' general characteristics, except for study major $(p<0.001)$, weight status $(p<0.01)$, academic performance $(\mathrm{p}<$ 0.001 ), and presence of nutrition-related diseases (in the students or their family) $(\mathrm{p}<0.001)$ (Table 1).

\section{Food and nutrition literacy status and its correlates}

Mean total FNL score and its domains and dimensions are shown in Fig. 1. The mean \pm SD of the total FNL score was $52.1 \pm 10.96$ with no significant difference between boys and girls. Girls had significantly higher functional score than boys, while food label score was significantly higher in boys as compared to girls. Among the FNL dimension, the highest score belonged to functional skills $(58.85 \pm 18.66)$, while the mean score of interactive skills was the lowest $(43.06 \pm 18.40)$.

The results of the bivariate analysis of FNL determinant factors are presented in Tables 2 and 3. As shown in Table 2, a significant positive but poor correlation was found between knowledge score and academic performance $(r=0.188)$, mother education $(r=0.113)$, and SES score $(r=0.153)$. Higher BMI-for-age Z-score was also significantly correlated with functional scores $(r=0.115)$. The correlation between BMI-for-age Z-score and total FNL, knowledge, and skill score was statistically significant but negligible $(r<0.1)$. Father education and job position had also a significant but negligible correlation with knowledge $(r=0.084)$ and critical analysis of information score $(r=0.084)$, respectively. As presented in Table 3, the mean knowledge score was significantly lower in students who studied Literature and Humanities compared to those who majored in Natural Sciences and Mathematics; and in students of public versus private schools $(p<0.05)$. Critical analysis of information scores was significantly higher in students of public schools compared to those in private schools and in students whose major was mathematics compared to those who studied Natural sciences and in students who suffered from a nutrition-related disease compared to healthy ones $(\mathrm{p}<0.05)$. Regarding food label reading skill, participants who studied mathematics had a significantly higher mean score than those whose major was literature and humanity $(p<0.05)$.

Possible socio-demographic predictors of FNL and its domains and dimensions were examined through multivariate analysis (Table 4). The probability of high knowledge score was significantly higher among students who studied Natural Sciences compared to those whose major were Literature and Humanities $(\mathrm{OR}=1.73, \mathrm{CI}=$ 1.09-2.75). Higher SES score $(\mathrm{OR}=1.20, \mathrm{CI}=1.01-1.44)$ and better academic performance $(\mathrm{OR}=1.13, \mathrm{CI}=1.06$ 1.20) were also associated with increased probability of having higher knowledge score $(\mathrm{OR}=1.13, \mathrm{CI}=1.06$ 1.20). Better academic performance was associated with lower probability of high functional $(\mathrm{OR}=0.93, \mathrm{CI}=$ $0.87-0.99)$ and interactive ( $\mathrm{OR}=0.92, \mathrm{CI}=0.87-0.98)$ score. In female students, the probability of high food label reading skill was $55 \%$ less than male students $(p<$ 0.001). Having a nutrition related-disease in the family members increased the probability of higher food label reading skill by $48 \%(p<0.05)$.

\section{Discussion}

The findings of the present study showed that mean score in none of the FNL domains and dimensions was above the adequate level $(\geq 60)$ which indicates that the FNL status of Iranian youth needs improvement. Considering the fact that the study participants were senior high-school students who had completed formal education, their FNL status conveys key messages for the educational system and could reflect the weakness points of current school curricula in improving food and nutrition literacy among students.

There were no significant differences between boys and girls scores in overall FNL and its dimensions, except for functional and food label reading skill scores. The mean score of functional skills was slightly higher in girls compared to boys; however, after adjusting for other factors in the multivariate analysis, gender was not a significant predictor of functional skills anymore. On the other hand, with regard to food label reading skill, gender was a strong predictor even after adjusting the effect of all other possible predictors in multivariate analysis. The results showed that boys scored higher in reading and interpreting food labels. Reviewing the available literature indicate that there is no consistent gender difference in food label use or interpreting skills. Some 
Table 1 Demographic and anthropometric characteristics of study participants

\begin{tabular}{|c|c|c|c|c|}
\hline & $\mathrm{n}(\%)$ or $\mathrm{M}$ & & & \\
\hline & Total & Girls & Boys & $P$ value \\
\hline City district & & & & $0.472^{\mathrm{a}}$ \\
\hline High SES district & $327(52.2)$ & $168(54.0)$ & $159(50.5)$ & \\
\hline Middle SES district & $154(24.6)$ & $70(22.5)$ & $84(26.7)$ & \\
\hline Low SES district & $145(23.2)$ & $73(23.5)$ & $72(22.9)$ & \\
\hline School type & & & & $0.459^{\mathrm{a}}$ \\
\hline Public & $441(70.4)$ & $218(70.1)$ & $223(70.8)$ & \\
\hline Private & $185(29.6)$ & $93(29.9)$ & $92(29.2)$ & \\
\hline Major & & & & $<0.001$ \\
\hline Literature and Humanities & $144(23.0)$ & $89(28.6)$ & $55(17.5)$ & \\
\hline Natural Sciences & $215(34.3)$ & $127(40.8)$ & $88(27.9)$ & \\
\hline Mathematics & $267(42.7)$ & $95(30.5)$ & $172(54.6)$ & \\
\hline Father education & & & & $0.389^{a}$ \\
\hline Illiterate & $11(1.8)$ & $7(2.3)$ & $4(1.3)$ & \\
\hline Less than high-school diploma & $127(20.3)$ & $56(20.9)$ & $62(19.7)$ & \\
\hline High-school diploma & $290(46.3)$ & $152(48.9)$ & $138(43.8)$ & \\
\hline Associate degree or bachelor & $136(21.7)$ & $60(19.3)$ & $76(24.1)$ & \\
\hline MSc or PhD & $61(9.7)$ & $27(8.7)$ & $34(10.8)$ & \\
\hline Dead & $1(0.2)$ & 0 & $1(0.3)$ & \\
\hline Mother education & & & & $0.492^{\mathrm{a}}$ \\
\hline Illiterate & $15(2.4)$ & $7(2.3)$ & $8(2.5)$ & \\
\hline Less than high-school diploma & $130(20.8)$ & $72(23.2)$ & $58(18.4)$ & \\
\hline High-school diploma & $319(51.0)$ & $159(51.1)$ & $160(50.8)$ & \\
\hline Associate degree or bachelor & $138(22.0)$ & $61(19.6)$ & $77(24.4)$ & \\
\hline MSc or PhD & $24(3.8)$ & $12(3.9)$ & $12(3.8)$ & \\
\hline Father job position ${ }^{c}$ & & & & $0.389^{\mathrm{a}}$ \\
\hline Unemployed & $9(1.4)$ & $4(1.3)$ & $5(1.6)$ & \\
\hline Worker & $77(12.3)$ & $40(12.9)$ & $37(117)$ & \\
\hline Clerk & $151(24.1)$ & $69(22.2)$ & $82(26.0)$ & \\
\hline Self-employed jobs & $232(37.1)$ & $114(36.7)$ & $118(37.5)$ & \\
\hline High income jobs & $69(11.0)$ & $43(13.8)$ & $26(8.3)$ & \\
\hline Retired & $73(11.7)$ & $33(10.6)$ & $40(12.7)$ & \\
\hline Dead or divorced & $15(2.4)$ & $8(2.6)$ & $7(2.2)$ & \\
\hline Mother job position & & & & $0.193^{\mathrm{a}}$ \\
\hline Unemployed & $522(83.4)$ & $261(83.9)$ & $261(82.9)$ & \\
\hline Worker & $8(1.3)$ & $6(1.9)$ & $2(0.6)$ & \\
\hline Clerk & $68(10.9)$ & $27(8.7)$ & $41(13.0)$ & \\
\hline Self-employed jobs & $14(2.2)$ & $7(2.3)$ & $7(2.2)$ & \\
\hline High income jobs & $6(1.0)$ & $5(1.6)$ & $1(0.3)$ & \\
\hline Retired & $7(1.1)$ & $4(1.3)$ & $3(1.0)$ & \\
\hline Dead or divorced & $1(0.2)$ & $1(3.0)$ & 0 & \\
\hline Weight status (based on BMl-for-age & & & & $0.009^{\mathrm{a}}$ \\
\hline Normal weight (z-scores <1SD) & $337(56.4)$ & $177(61)$ & $160(51.9)$ & \\
\hline Overweight (1SD $\leq$ z-scores <2SD) & $147(24.6)$ & $71(24.8)$ & $75(24.4)$ & \\
\hline
\end{tabular}


Table 1 Demographic and anthropometric characteristics of study participants (Continued)

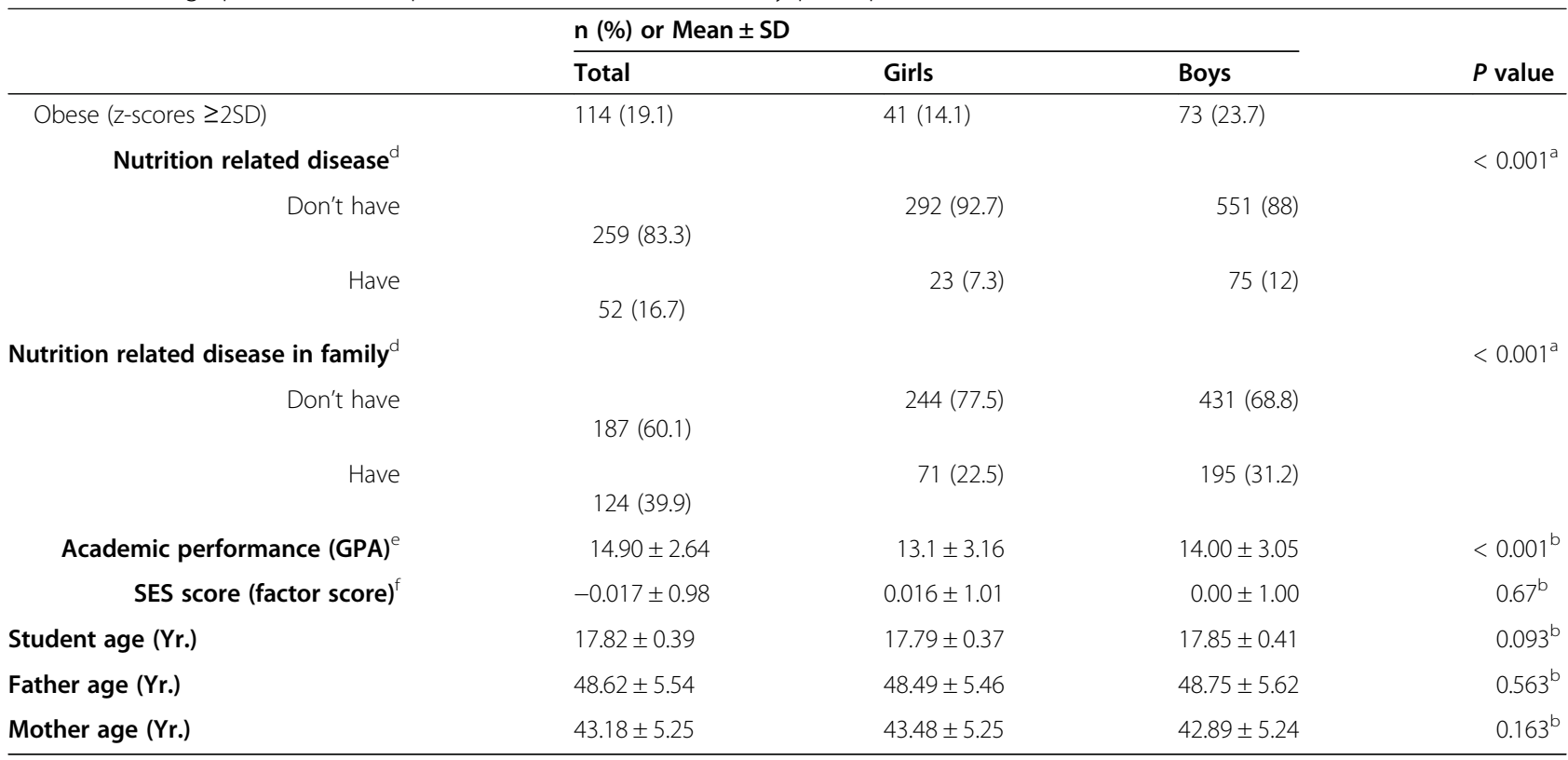

a Chi-squared test

b Student's t-test

'Workers are defined as people who may not have a permanent jobt and income (low-income job); Clerks are those who employed in an office or company with a consistent income (relatively low income); self-employed jobs such as shopkeepers, barbers, car mechanics, etc.; high-income jobs included factory owner, Jewelry storeowner, etc.

${ }^{\mathrm{d}}$ Nutrition related disease; suffering from diabetes, hypertension, dyslipidemia, cardiovascular diseases and cancer eGPA: grade point average (within potential range of 0 to 20)

${ }^{f} \mathrm{SES}$ has been calculated using principal component analysis (the factor score saved as the SES variable)

studies did not show any gender differences [24-26], while some indicated that females more frequently used or correctly interpreted food labels compared to males [27-29]. According to the literature, women seem to use food labels more frequently than men [25, 27, 28]; however, inconsistency between studies exist regarding interpreting and understanding food labels [24-26, 29], suggesting that other factors such as age, education level, nutrition knowledge, etc., may affect gender differences.
Based on bivariate analysis, mother education level, studying in private school and higher SES score were significantly associated with higher food and nutrition knowledge score. Multivariate analysis confirmed these results; as increasing SES score was associated with a higher likelihood of higher knowledge score. Consistent results have been reported in several studies [12, 30-33]. Aihara et al. indicated that higher educational level and economic status was associated with adequate nutrition

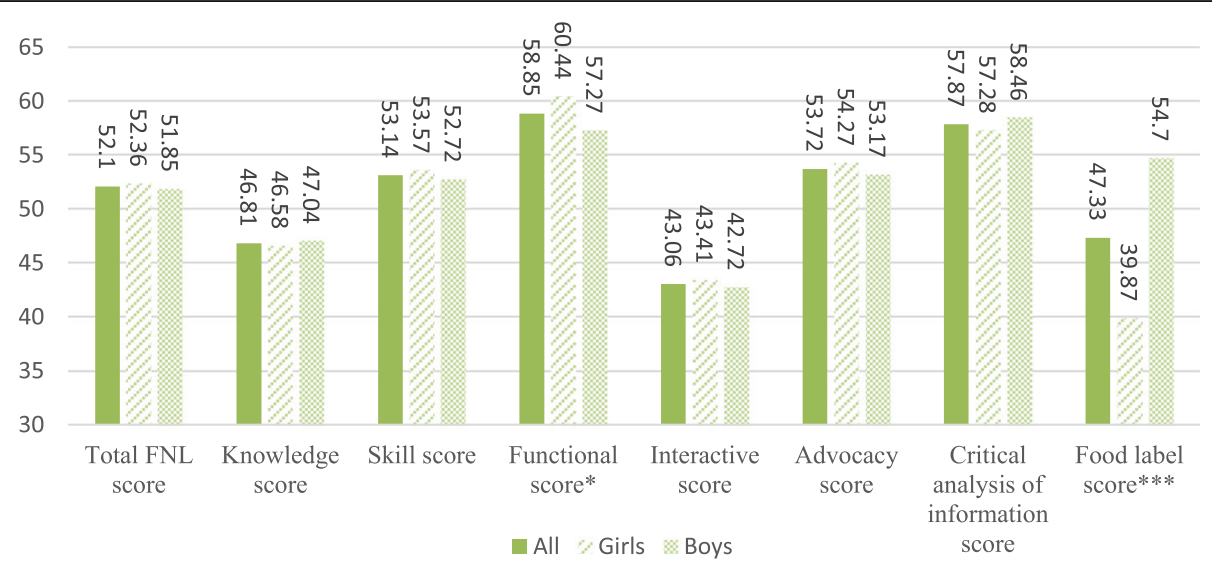

Fig. 1 Mean scores of food and nutrition literacy and its domains and dimensions. * Mean score is significantly different between boys and girls at $p<0.05$, using student's t-test. ${ }^{* *}$ Mean score is significantly different between boys and girls at $p<0.001$, using student's t-test 
Table 2 Correlation coefficient between food and nutrition literacy, its domains and dimensions and some possible determinant factors

\begin{tabular}{|c|c|c|c|c|c|c|c|c|}
\hline & \multicolumn{8}{|c|}{ Correlation coefficient } \\
\hline & \multicolumn{3}{|c|}{ Total FNL and its domains } & \multicolumn{5}{|c|}{ Skill dimensions } \\
\hline & $\begin{array}{l}\text { Total } \\
\text { FNL }\end{array}$ & $\begin{array}{l}\text { Knowledge } \\
\text { score }\end{array}$ & $\begin{array}{l}\text { Skill } \\
\text { score }\end{array}$ & $\begin{array}{l}\text { Functional } \\
\text { score }\end{array}$ & $\begin{array}{l}\text { Interactive } \\
\text { score }\end{array}$ & $\begin{array}{l}\text { Critical analysis of } \\
\text { information score }\end{array}$ & $\begin{array}{l}\text { Advocacy } \\
\text { score }\end{array}$ & $\begin{array}{l}\text { Food label } \\
\text { reading score }\end{array}$ \\
\hline $\begin{array}{l}\text { Academic } \\
\text { performances }{ }^{a}\end{array}$ & 0.023 & $0.188^{* * *}$ & -0.034 & -0.029 & -0.070 & -0.001 & -0.008 & -0.004 \\
\hline $\begin{array}{l}\text { Mother education } \\
\mathrm{b}\end{array}$ & 0.024 & $0.113^{* *}$ & -0.005 & 0.032 & -0.009 & 0.050 & -0.011 & 0.041 \\
\hline Father education ${ }^{\mathrm{b}}$ & 0.048 & $0.084^{*}$ & 0.031 & 0.036 & 0.023 & 0.047 & -0.024 & 0.074 \\
\hline $\begin{array}{l}\text { Mother job } \\
\text { position }{ }^{b}\end{array}$ & 0.002 & 0.074 & -0.016 & 0.008 & -0.006 & -0.060 & -0.041 & 0.027 \\
\hline $\begin{array}{l}\text { Father job } \\
\text { position }^{b}\end{array}$ & 0.041 & 0.066 & 0.028 & 0.016 & 0.001 & $0.084^{*}$ & -0.004 & -0.047 \\
\hline $\begin{array}{l}\text { BMl for age Z- } \\
\text { score }^{\text {a }}\end{array}$ & $0.098^{*}$ & $0.091^{*}$ & $0.084^{*}$ & $0.115^{*}$ & 0.044 & 0.014 & -0.013 & 0.057 \\
\hline SES score ${ }^{a}$ & 0.065 & $0.153^{* * *}$ & 0.029 & 0.056 & 0.029 & 0.021 & -0.071 & 0.047 \\
\hline
\end{tabular}

a values are Pearson correlation coefficient

b values are Spearman correlation coefficient

${ }^{*} P<0.05$

${ }^{* *} P<0.01$

${ }^{* * *} P<0.001$

literacy in elderly Japanese [30]. Although they used the term "nutrition literacy", but their questionnaire only assessed nutrition knowledge. Similarly, other studies have shown higher education level [12, 31-33] and job position [12, 31, 32] were positively associated with nutrition knowledge. The necessity of food and nutrition knowledge as a prerequisite for dietary changes [8], although not sufficient, calls the need for more emphasis on nutrition educational programs targeted at lower SES groups.

Table 3 Mean score of food and nutrition literacy, its domains and dimensions by categories of some possible determinant factors

\begin{tabular}{|c|c|c|c|c|c|c|c|c|}
\hline & \multicolumn{8}{|l|}{ Mean \pm SD } \\
\hline & \multicolumn{3}{|c|}{ Total FNL and its domains } & \multicolumn{5}{|c|}{ Skill dimensions } \\
\hline & Total FNL & $\begin{array}{l}\text { Knowledge } \\
\text { score }\end{array}$ & Skill score & $\begin{array}{l}\text { Functional } \\
\text { score }\end{array}$ & $\begin{array}{l}\text { Interactive } \\
\text { score }\end{array}$ & $\begin{array}{l}\text { Critical analysis of } \\
\text { information score }\end{array}$ & $\begin{array}{l}\text { Advocacy } \\
\text { score }\end{array}$ & $\begin{array}{l}\text { Food label } \\
\text { reading score }\end{array}$ \\
\hline \multicolumn{9}{|l|}{ Major $^{*}$} \\
\hline $\begin{array}{l}\text { Literature and } \\
\text { Humanities }\end{array}$ & $51.88 \pm 11.5$ & $42.79 \pm 15.3^{a}$ & $53.99 \pm 12.3$ & $60.37 \pm 18.7$ & $45.28 \pm 19.5$ & $56.87 \pm 15.0$ & $54.41 \pm 19.8$ & $40.50 \pm 31.8^{a}$ \\
\hline $\begin{array}{l}\text { Natural } \\
\text { Sciences }\end{array}$ & $51.82 \pm 10.2$ & $48.97 \pm 12.7^{b}$ & $53.44 \pm 11.1$ & $59.63 \pm 17.6$ & $43.23 \pm 17.7$ & $55.99 \pm 16.2^{a}$ & $55.06 \pm 20.4$ & $44.74 \pm 33.9$ \\
\hline Mathematics & $51.64 \pm 11.1$ & $47.24 \pm 15.4^{b}$ & $52.45 \pm 12.1$ & $57.40 \pm 19.3$ & $41.72 \pm 18.1$ & $59.92 \pm 16.7^{b}$ & $52.27 \pm 20.1$ & $50.93 \pm 32.47^{b}$ \\
\hline \multicolumn{9}{|l|}{ School type ${ }^{\dagger}$} \\
\hline public & $51.99 \pm 11.1$ & $45.83 \pm 14.4^{a}$ & $53.23 \pm 12.1$ & $58.81 \pm 18.2$ & $43.44 \pm 18.6$ & $56.99 \pm 15.3^{a}$ & $54.64 \pm 20.1$ & $47.69 \pm 31.6$ \\
\hline private & $52.38 \pm 10.4$ & $49.14 \pm 15.1^{b}$ & $52.94 \pm 11.1$ & $58.95 \pm 19.5$ & $42.15 \pm 17.7$ & $60.00 \pm 18.1^{b}$ & $51.49 \pm 20.1$ & $46.48 \pm 36.2$ \\
\hline \multicolumn{9}{|c|}{ Nutrition related disease ${ }^{\dagger}$} \\
\hline Don't have & $51.95 \pm 11.0$ & $46.58 \pm 14.6$ & $52.98 \pm 11.9$ & $58.36 \pm 18.6$ & $43.32 \pm 18.4$ & $57.39 \pm 16.1^{a}$ & $53.73 \pm 20.2$ & $48.03 \pm 32.8$ \\
\hline Have & $53.44 \pm 10.5$ & $48.49 \pm 15.1$ & $54.34 \pm 11.1$ & $62.44 \pm 18.7$ & $41.11 \pm 17.7$ & $61.44 \pm 16.8^{b}$ & $53.60 \pm 20.1$ & $42.22 \pm 34.3$ \\
\hline \multicolumn{9}{|c|}{ Nutrition related disease in family ${ }^{\dagger}$} \\
\hline Don't have & $51.87 \pm 10.9$ & $46.63 \pm 14.8$ & $52.91 \pm 11.8$ & $58.25 \pm 18.1$ & $42.77 \pm 18.7$ & $58.36 \pm 15.99$ & $53.51 \pm 20.2$ & $47.09 \pm 33.0$ \\
\hline Have & $52.61 \pm 11.0$ & $47.21 \pm 14.4$ & $53.65 \pm 11.8$ & $60.16 \pm 19.8$ & $43.69 \pm 17.7$ & $56.80 \pm 16.8$ & $54.17 \pm 20.2$ & $47.86 \pm 33.1$ \\
\hline
\end{tabular}

Nutrition related disease; suffering from diabetes, hypertension, dyslipidemia, cardiovascular diseases and cancer

a, b Values with different superscript are significantly different $(p<0.05)$

*Statistical significance of means difference was examined using One-Way ANOVA

${ }^{\dagger}$ Statistical significance of means difference was examined using Student's t-test 
Table 4 Factor associated with higher FNL, its domains and dimensions

\begin{tabular}{|c|c|c|c|c|c|c|c|c|}
\hline & \multicolumn{8}{|c|}{ Odds ratio $(0.95 \% \text { confidence interval })^{a}$} \\
\hline & \multicolumn{3}{|c|}{ Total FNL and its domains } & \multicolumn{5}{|c|}{ Skill dimensions } \\
\hline & $\begin{array}{l}\text { High } \\
\text { total } \\
\text { FNL }\end{array}$ & $\begin{array}{l}\text { High } \\
\text { knowledge } \\
\text { score }\end{array}$ & $\begin{array}{l}\text { High } \\
\text { skill } \\
\text { score }\end{array}$ & $\begin{array}{l}\text { High } \\
\text { functional } \\
\text { score }\end{array}$ & $\begin{array}{l}\text { High } \\
\text { interactive } \\
\text { score }\end{array}$ & $\begin{array}{l}\text { High critical analysis of } \\
\text { information score }\end{array}$ & $\begin{array}{l}\text { High } \\
\text { advocacy } \\
\text { score }\end{array}$ & $\begin{array}{l}\text { High Food label } \\
\text { reading score }\end{array}$ \\
\hline \multicolumn{9}{|l|}{ gender } \\
\hline boy & Reference & Reference & Reference & Reference & Reference & Reference & Reference & Reference \\
\hline girl & $\begin{array}{l}1.17 \\
(0.76- \\
1.82)\end{array}$ & $\begin{array}{l}0.78(0.53- \\
1.13)\end{array}$ & $\begin{array}{l}1.29 \\
(0.83- \\
2.09)\end{array}$ & $\begin{array}{l}1.33(0.86- \\
2.05)\end{array}$ & $\begin{array}{l}1.19(0.82- \\
1.72)\end{array}$ & $1.07(0.67-1.70)$ & $\begin{array}{l}1.19(0.81- \\
1.76)\end{array}$ & $\underset{* * * *}{0.45}(0.31-0.67)$ \\
\hline \multicolumn{9}{|l|}{ Major } \\
\hline $\begin{array}{l}\text { Literature and } \\
\text { Humanities }\end{array}$ & Reference & Reference & Reference & Reference & Reference & Reference & Reference & Reference \\
\hline $\begin{array}{l}\text { Natural } \\
\text { Sciences }\end{array}$ & $\begin{array}{l}1.411 \\
(0.81- \\
2.43)\end{array}$ & $\begin{array}{l}1.73(1.09- \\
2.75)^{*}\end{array}$ & $\begin{array}{l}1.16 \\
(0.67- \\
2.00)\end{array}$ & $\begin{array}{l}1.10(0.63- \\
1.13)\end{array}$ & $\begin{array}{l}0.92(0.58- \\
1.44)\end{array}$ & $0.70(0.39-1.24)$ & $\begin{array}{l}0.98(0.60- \\
1.59)\end{array}$ & $1.33(0.84-2.10)$ \\
\hline Mathematics & $\begin{array}{l}0.80 \\
(0.48- \\
1.34)\end{array}$ & $\begin{array}{l}1.39(0.88- \\
2.20)\end{array}$ & $\begin{array}{l}0.91 \\
(0.53- \\
1.54)\end{array}$ & $\begin{array}{l}0.82(0.48- \\
1.40)\end{array}$ & $\begin{array}{l}0.82(0.52- \\
1.29)\end{array}$ & $0.95(0.53-1.72)$ & $\begin{array}{l}0.87(0.54- \\
1.61)\end{array}$ & $1.51(0.95-1.2 .38)$ \\
\hline $\begin{array}{l}\text { Academic } \\
\text { performance }\end{array}$ & $\begin{array}{l}1.02 \\
(0.96- \\
1.10)\end{array}$ & $\begin{array}{l}1.13(1.06- \\
1.20)^{* * *}\end{array}$ & $\begin{array}{l}0.98 \\
(0.92- \\
1.05)\end{array}$ & $\begin{array}{l}0.93(0.87- \\
0.99)^{*}\end{array}$ & $\begin{array}{l}0.92(0.87- \\
0.98)^{*}\end{array}$ & $0.98(0.91-1.06)$ & $\begin{array}{l}1.02(0.96- \\
1.08)\end{array}$ & $1.03(0.97-1.09)$ \\
\hline SES score & $\begin{array}{l}1.20 \\
(0.98- \\
1.47)\end{array}$ & $\begin{array}{l}1.20(1.01- \\
1.44)^{*}\end{array}$ & $\begin{array}{l}0.97 \\
(0.79- \\
1.19)\end{array}$ & $\begin{array}{l}1.07(0.87- \\
1.31)\end{array}$ & $\begin{array}{l}1.02(0.86- \\
1.22)\end{array}$ & $1.06(0.85-1.32)$ & $\begin{array}{l}0.85(0.71- \\
1.02)\end{array}$ & $0.99(0.83-1.18)$ \\
\hline \multicolumn{9}{|c|}{ Nutrition-related disease } \\
\hline Don't have & Reference & Reference & Reference & Reference & Reference & Reference & Reference & Reference \\
\hline Have & $\begin{array}{l}1.05 \\
(0.56- \\
1.96)\end{array}$ & $\begin{array}{l}0.83(0.49- \\
1.43)\end{array}$ & $\begin{array}{l}1.14 \\
(0.62- \\
2.09)\end{array}$ & $\begin{array}{l}0.71(0.36- \\
1.40)\end{array}$ & $\begin{array}{l}1.71(0.99- \\
2.95)\end{array}$ & $0.67(0.32-1.38)$ & $\begin{array}{l}1.04(0.59- \\
1.81)\end{array}$ & $1.29(0.75-2.2)$ \\
\hline \multicolumn{9}{|c|}{ Nutrition-related disease in family } \\
\hline Don't have & Reference & Reference & Reference & Reference & Reference & Reference & Reference & Reference \\
\hline Have & $\begin{array}{l}0.86 \\
(0.56- \\
1.96)\end{array}$ & $\begin{array}{l}1.07(0.73- \\
1.56)\end{array}$ & $\begin{array}{l}0.82 \\
(0.53- \\
1.27)\end{array}$ & $\begin{array}{l}0.98(0.63- \\
1.52)\end{array}$ & $\begin{array}{l}1.28(0.88- \\
1.85)\end{array}$ & $0.83(0.52-1.32)$ & $\begin{array}{l}0.96(0.65- \\
1.41)\end{array}$ & $1.48(1.01-1.64)$ * \\
\hline BMI for age & $\begin{array}{l}1.11 \\
(0.96- \\
1.29)\end{array}$ & $\begin{array}{l}1.09(0.96- \\
1.23)\end{array}$ & $\begin{array}{l}1.07 \\
(0.92- \\
1.23)\end{array}$ & $\begin{array}{l}1.06(0.91- \\
1.22)\end{array}$ & $\begin{array}{l}1.03(0.911- \\
1.16)\end{array}$ & $1.03(0.88-1.20)$ & $\begin{array}{l}1.01(0.89- \\
1.15)\end{array}$ & $1.09(0.96-1.24)$ \\
\hline
\end{tabular}

FNL food and nutrition literacy. Nutrition-related disease; suffering from diabetes, hypertension, dyslipidemia, cardiovascular diseases and cancer

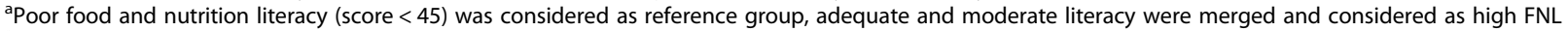

${ }^{*} P<0.05$

${ }^{* * *} P<0.001$

Academic performance was also associated with higher knowledge score, but surprisingly with lower functional and interactive scores. This may be due to the fact that current high school curriculums and textbooks in the country have relatively little on food and nutrition which is dominantly focused on knowledge aspects [11]. Besides, students with better academic performance due to heavy school workload, may have limited time or interest to develop their food and nutrition-related skills i.e. food shopping, preparation, and cooking (functional skills) or interact with others about food and nutrition (interactive skills). This may be especially more relevant in our study participants who were senior high-school students preparing for the university entrance exam. Further research is needed to make a more reliable conclusion in this regard.

The possibility of higher knowledge score was significantly higher in students who studied Natural Sciences compared to those whose major were Literature and $\mathrm{Hu}$ manities. Food and nutrition-related topics are more likely to be discussed in the Natural Sciences courses than other majors. A recent analysis of the content of high school textbooks in Iran showed that food and nutrition-related topics have been addressed more frequently in textbooks of Natural Sciences than other majors [11] which confirmed the results of the current study. 
The weight and health status of the subjects were also examined as possible determinants of FNL and its dimensions. Higher BMI was correlated with higher functional score in bivariate analysis. However, after controlling for the effect of other possible predictors in multivariate analysis, this association was not significant anymore. The relationship between weight status and FNL has been addressed in a number of studies [12, 15, $20,30,34,35]$; however, the results have not been consistent. In some studies, people with higher BMI have had a lower level of FNL [20,34], while in some others non-significant $[12,15,30]$ or positive [35] association between BMI and FNL has been reported. These investigations have been conducted among different age and sex groups that may partly explain this inconsistency in findings. In a study conducted by Kubiet et al. among adolescents [15], multivariate analysis showed no significant association between weight status and FNL, which is consistent with our findings. However, the limited number of studies, all with cross-sectional design makes it hard to make a conclusion.

In the current study, the presence of nutrition-related diseases in a family member predicted the possibility of higher food label reading skill of the students. Previous reports have also been indicated that people who suffer from nutrition-related diseases e.g. hypertension, diabetes, cardiovascular disease, etc., pay more attention to food labels [36]. People with nutrition-related chronic diseases and their families have more concerns about diet and may want to limit the consumption of some specific dietary components like calories, sugar, fat, salt, etc. These concerns could explain higher food label interpreting skills among people with chronic diseases and their families.

To the best of our knowledge, this is the first study assessing the FNL status of Iranian senior high-school students by a valid multidimensional tool. However, this study had some limitations that need to be taken into consideration. First, its cross-sectional design makes it impossible to interpret the direction of the associations. Moreover, the determinant factors examined in the current study could not explain the variation in score of the skill domain and its dimensions well. It seems that more complex factors affect FNL related skills which had not been included in our study. For example, food skills may be affected by socio-cultural norms which were not assessed in the present study. Therefore, in order to explore possible determinant factors of the FNL skill domain, further research especially with qualitative design could provide more insights. Finally, this study conducted among senior high-school students in Tehran; therefore, its results may not be generalized to other age groups or different populations.
In conclusion, the present study showed that Iranian senior high-school students have relatively low food and nutrition-related knowledge and skills. Among possible determinant factors examined, study major, academic performance and SES were significant predictors of youth's food and nutrition knowledge; and male gender and having nutrition-related diseases in family members were determinant factors of higher food label reading skill. Further studies are recommended to identify other possible factors related to youth's FNL. The findings reemphasize the need for evaluating current formal education curriculums with regard to food and nutrition knowledge and skill development as an important competent of life skills. Also, relatively low FNL level among senior high-school students highlighted the need for future studies focusing on FNL promoting interventions in high school students in Iran.

\section{Abbreviations}

NCDs: Non-communicable diseases; FNL: Food and nutrition literacy; FNLA T: Food and Nutrition Literacy Assessment Tool; GPA: Grade point average

\section{Supplementary Information}

The online version contains supplementary material available at https://doi. org/10.1186/s40795-021-00426-2.

Additional file 1. Identified domains, dimensions and sub-dimensions of Food and Nutrition Literacy for Iranian youth.

\section{Acknowledgements}

The authors thank Mahnaz Mahmudi and Atefeh Habbi for their contribution in data collection.

\section{Authors' contributions}

The authors' contributions are as follow: M. A., N. O., E. Sh. and H. E. Z., contributed to the designing this work. M. A., N. O., A. D., B. AE. and M. M. had role in carrying out this study. Statistical analysis was performed by M. A and H. E. Z. Drafting the manuscript was performed by M. A and N. O. all authors contributed in revision of manuscript and approved the content of submitted manuscript.

\section{Funding}

This study was funded by National Nutrition and Food Technology Research Institute (NNFTRI).

\section{Availability of data and materials \\ The datasets used and/or analysed during the current study are available from the corresponding author on reasonable request.}

\section{Declarations}

Ethics approval and consent to participate

The study protocol received ethical approval of National Nutrition and Food Technology Research Institute (NNFTRI) ethical committee (IR.SBMU.nnftri. Rec.1396.166). All methods were performed according to the relevant guidelines and regulations. Written informed consent was obtained from all students and their parents.

Consent for publication

Not applicable.

Competing interests

The authors declare that they have no conflict of interest. 


\section{Author details}

${ }^{1}$ Student Research Committee, Department of Community Nutrition, National Nutrition and Food Technology Research Institute and Faculty of Nutrition Sciences and Food Technology, Shahid Beheshti University of Medical Sciences, Tehran, Iran. ${ }^{2}$ Department of Community Nutrition, National Nutrition and Food Technology Research Institute (NNFTRI) and Faculty of Nutrition Sciences and Food Technology, Shahid Beheshti University of Medical Sciences, West Arghavan St. Farahzadi Blvd., Sharake Qods, Tehran, Iran. ${ }^{3}$ Department of Health Education and Promotion, School of Public Health, Tehran University of Medical Sciences, Tehran, Iran. ${ }^{4}$ Gastrointestinal and Liver Disease Research Center, Iran University of Medical Sciences, Tehran, Iran.

Received: 14 January 2021 Accepted: 30 March 2021

Published online: 04 June 2021

\section{References}

1. Noncommunicable diseases: Unhealthy diet. World Health Organization; 2019. http://www.emro.who.int/noncommunicable-diseases/causes/unhea Ithy-diets.html/. Accessed 20 Aug 2019.

2. NCD mortality and morbidity. World Health Organization; 2019. https:// www.who.int/gho/ncd/mortality_morbidity/en/. Accessed 20 Aug 2019.

3. Afshin A, Sur PJ, Fay KA, Cornaby L, Ferrara G, Salama JS, et al. Health effects of dietary risks in 195 countries, 1990-2017: a systematic analysis for the global burden of disease study 2017. Lancet. 2019;393(10184):1958-72. https://doi.org/10.1016/S0140-6736(19)30041-8.

4. UNICEF. The State of the World's Children 2019: Children, food and nutrition--growing well in a changing world. New York: UNICEF; 2019.

5. Akbari F, Azadbakht L. A systematic review on diet quality among Iranian youth: focusing on reports from Tehran and Isfahan. Arch Iran Med. 2014; 17(8):574-84.

6. Sleddens EF, Kroeze W, Kohl LF, Bolten LM, Velema E, Kaspers PJ, et al. Determinants of dietary behavior among youth: an umbrella review. Int J Behav Nutr Phys Act. 2015;12(1):7. https://doi.org/10.1186/s12966-015-0164$\mathrm{x}$

7. Vaitkeviciute R, Ball LE, Harris N. The relationship between food literacy and dietary intake in adolescents: a systematic review. Public Health Nutr. 2015; 18(4):649-58. https://doi.org/10.1017/S1368980014000962.

8. Nelson SA. A systematic review of peer nutrition education in childhood and adolescence. Health Behav Policy Rev. 2014;1 (4):247-64. https://doi. org/10.14485/HBPR.1.4.1.

9. Vidgen HA, Gallegos D. Defining food literacy and its components. Appetite. 2014;76:50-9. https://doi.org/10.1016/j.appet.2014.01.010.

10. Velardo $\mathrm{S}$. The nuances of health literacy, nutrition literacy, and food literacy. J Nutr Educ Behav. 2015;47(4):385-9 e1. https://doi.org/10.1016/j. jneb.2015.04.328.

11. Arvand A, Dehghani M, Omidvar N, Ashoori M. Food and nutrition literacy: a neglected aspect in high school textbooks in Iran. Iranian J Nutr Sci Food Tech. 2018;13(4):29-38 [In Persian].

12. Cesur D, Sümer D. Nutrition literacy status of adults residing in Sivas province and its relationship with quality of life: a cross-sectional study from Turkey. Innovative J Med Health Sci. 2018;8(1):1-9.

13. Coffman MJ, La-Rocque S. Development and testing of the Spanish nutrition literacy scale. Hisp Health Care Int. 2012;10(4):168-74. https://doi. org/10.1891/1540-4153.10.4.168.

14. Cuy Castellanos D, Holcomb J. Food insecurity, financial priority, and nutrition literacy of university students at a mid-size private university. J Am Coll Heal. 2018;26:1-5.

15. D'Amato-Kubiet L. Nutrition literacy and demographic variables as predictors of adolescent weight status in a Florida county. Florida: University of Central Florida; 2013.

16. Doustmohammadian A, Keshavarz Mohammadi N, Omidvar N, Amini M, Abdollahi M, Eini-Zinab H, et al. Food and nutrition literacy (FNLIT) and its predictors in primary schoolchildren in Iran. Health Promot Int. 2018;34(5): 1002-13.

17. Fernandez MA. Food literacy and healthy diets of Canadian parents: associations and evaluation of the eat well campaign. Quebec: Laval University; 2019.

18. Joulaei H, Keshani P, Kaveh MH. Nutrition literacy as a determinant for diet quality amongst young adolescents: a cross sectional study. Prog Nutr. 2018;20(3):455-64.
19. Lee C-K, Liao L-L, Lai I-J, Chang L-C. Effects of a healthy-eater self-schema and nutrition literacy on healthy-eating behaviors among Taiwanese college students. Health Promot Int. 2017;34(2):269-76.

20. Mahmudiono T, Nindya TS, Andrias DR, Megatsari H, Rachmah Q, Rosenkranz RR. Comparison of maternal nutrition literacy, dietary diversity, and food security among households with and without double burden of malnutrition in Surabaya, Indonesia. Malays J Nutr. 2018;24(3):359-70.

21. Michou M, Panagiotakos DB, Lionis C, Costarelli V. Socioeconomic inequalities in relation to health and nutrition literacy in Greece. Int J Food Sci Nutr. 2019;1:1-7.

22. Krause C, Sommerhalder K, Beer-Borst S, Abel T. Just a subtle difference? Findings from a systematic review on definitions of nutrition literacy and food literacy. Health Promot Int. 2016;33(3):378-89.

23. Ashoori M, Omidvar N, Eini-Zinab $H$, et al. Development and validation of food and nutrition literacy assessment tool (FNLAT) for Iranian high-school graduates and youth. Int J Prev Med. 2020;11:158.

24. Jackey BA, Cotugna N, Orsega-Smith E. Food label knowledge, usage and attitudes of older adults. J Nutr Gerontol Geriatr. 2017;36(1):31-47. https:// doi.org/10.1080/21551197.2017.1280868.

25. Liu R, Hoefkens C, Verbeke W. Chinese consumers' understanding and use of a food nutrition label and their determinants. Food Qual Prefer. 2015;41: 103-11. https://doi.org/10.1016/j.foodqual.2014.11.007.

26. McCune RL, Lee $H$, Pohl JM. Assessing health literacy in safety net primary care practices. Appl Nurs Res. 2016;29:188-94. https://doi.org/10.1016/j.a pnr.2015.04.004

27. Christoph MJ, An R, Ellison B. Correlates of nutrition label use among college students and young adults: a review. Public Health Nutr. 2016; 19(12):2135-48. https://doi.org/10.1017/S1368980015003183.

28. Hess $R$, Visschers VH, Siegrist $M$. The role of health-related, motivational and sociodemographic aspects in predicting food label use: a comprehensive study. Public Health Nutr. 2012;15(3):407-14. https://doi.org/10.1017/S13 6898001100156X.

29. Clouston SA, Manganello JA, Richards M. A life course approach to health literacy: the role of gender, educational attainment and lifetime cognitive capability. Age Ageing. 2017;46(3):493-9. https://doi.org/10.1093/ageing/a fw229.

30. Aihara $Y$, Minai J. Barriers and catalysts of nutrition literacy among elderly Japanese people. Health Promot Int. 2011;26(4):421-31. https://doi.org/10.1 093/heapro/dar005

31. Dallongeville J, Marécaux N, Cottel D, Bingham A, Amouyel P. Association between nutrition knowledge and nutritional intake in middle-aged men from northern France. Public Health Nutr. 2001;4(1):27-33. https://doi.org/1 0.1079/PHN200052.

32. De Vriendt T, Matthys C, Verbeke W, Pynaert I, De Henauw S. Determinants of nutrition knowledge in young and middle-aged Belgian women and the association with their dietary behaviour. Appetite. 2009;52(3):788-92. https:// doi.org/10.1016/j.appet.2009.02.014.

33. Wardle J, Parmenter K, Waller J. Nutrition knowledge and food intake. Appetite. 2000;34(3):269-75. https://doi.org/10.1006/appe.1999.0311.

34. Gibbs HD, Kennett AR, Kerling EH, Yu Q, Gajewski B, Ptomey LT, et al. Assessing the nutrition literacy of parents and its relationship with child diet quality. J Nutr Educ Behav. 2016:48(7):505-9 e1. https://doi.org/10.1016/j. jneb.2016.04.006.

35. Taylor MK, Sullivan DK, Ellerbeck EF, Gajewski BJ, Gibbs HD. Nutrition literacy predicts adherence to healthy/unhealthy diet patterns in adults with a nutrition-related chronic condition. Public Health Nutr. 2019;22(12):2157-69. https://doi.org/10.1017/S1368980019001289.

36. Lewis JE, Arheart KL, LeBlanc WG, Fleming LE, Lee DJ, Davila EP, et al. Food label use and awareness of nutritional information and recommendations among persons with chronic disease. Am J Clin Nutr. 2009;90(5):1351-7. https://doi.org/10.3945/ajcn.2009.27684.

\section{Publisher's Note}

Springer Nature remains neutral with regard to jurisdictional claims in published maps and institutional affiliations. 